\title{
Outline of a medical genetics curriculum for internal medicine residency training programs
}

Douglas L. Riegert-Johnson, $M D^{1}$, Bruce R. Korf, MD, PhD ${ }^{2}$, Raye Lynn Alford, PhD ${ }^{3}$, Martin I. Broder, $M D^{4}$, Bronya J.B . Keats, $\mathrm{PhD}^{5}$, Kelly E. Ormond, MS, CGC ${ }^{6}$, Reed E. Pyeritz, MD, PhD ${ }^{7}$, and Michael S. Watson, $P h D^{8}$

\begin{abstract}
To keep pace with the rapid advances in medical genetics, internal medicine residency training programs need to train internists to develop new attitudes, knowledge bases, and skill sets. Currently, such programs have no medical genetics curriculum. Thus, to set a minimum standard for genetics education in the context of training in internal medicine, the Internal Medicine Residency Training Program Genetics Curriculum Committee was formed, with members representing professional organizations of medical geneticists, internists, genetic counselors, internal medicine and genetics residency program directors, and internal medicine residents. The committee's task was to develop a concise outline of a medical genetics curriculum for residents in internal medicine in accordance with requirements of the Residency Review Committee for Internal Medicine of the Accreditation Council for Graduate Medical Education. The curriculum outline was drafted and circulated for comment. Before publication, the final document was approved by those member organizations that had a policy of approving curricula. Key learning objectives of the curriculum include appreciation of the rapid advances in genetics, the need for lifelong learning, the need for referral, and the role of genetic counselors and medical geneticists, as well as developing the ability to construct and analyze a three-generation pedigree. A wide variety of teaching methods can be useful in these regards, including didactic lectures, multimedia CD- ROMs, and clinical experience. Teaching should be related to clinical experiences whenever possible. The curriculum developed by the committee and presented in this article will assist in teaching residents the attitudes, knowledge, and skills they will require. Genet Med 2004:
\end{abstract}

6(6):543-547.

Key Words: curriculum, genetics, graduate education, internal medicine, medical education

Traditionally, internal medicine residency training programs have not included a medical genetics curriculum because, until recently, medical genetics was perceived to be limited to the care of children with rare disorders. However, with the sequencing of the human genome and other recent advances, medical genetics has shifted from rare to common disorders and from children to all age groups. Increasingly, internal medicine residents require an understanding of genetic testing, genetic counseling, pharmacogenetics, gene therapy, novel treatments, and other concepts. They will also require the skills to communicate these genetic concepts to referring physicians, other health professionals, and patients who have little or no understanding of genetics.

\footnotetext{
From the McKusick-Nathans Institute of Genetic Medicine ${ }^{1}$, Johns Hopkins Hospital, Baltimore, Maryland; University of Alabama School of Medicine ${ }^{2}$, Birmingham, Alabama; Baylor College of Medicine ${ }^{3}$, Houston, Texas; Baystate Medical Center ${ }^{4}$, Springfield, Massachusetts; Louisiana State University ${ }^{5}$, New Orleans, Louisiana; Northwestern University ${ }^{6}$, Chicago, Illinois; University of Pennsylvania School of Medicine ${ }^{7}$, Philadelphia, Pennsylvania; American College of Medical Genetics ${ }^{8}$, Bethesda, Maryland.

Douglas L. Riegert-Johnson, MD, Johns Hopkins Hospital, McKusick-Nathans Institute of Genetic Medicine, Blalock 1008, 600 North Wolfe St, Baltimore, MD 21287. E-mail: drieger2@jhmi.edu.
}

DOI: 10.1097/01.GIM.0000144561.77590.85
The Accreditation Council for Graduate Medical Education (ACGME) oversees graduate medical education in the United States. Residency review committees of the ACGME accredit training programs in each specialty. The Residency Review Committee for Internal Medicine (RRC-IM) has created guidelines for internal medicine residency training program curricula that now require internal medicine training programs to have a medical genetics component. ${ }^{1}$

The American Board of Internal Medicine (ABIM), which confers certification on internists, does not mention medical genetics in its current examination blueprint. However, the ABIM has joined with the American Board of Medical Genetics (ABMG), which certifies medical geneticists, to approve a combined internal medicine/medical genetics residency training program.

We formed the self appointed Internal Medicine Residency Training Program Genetics Curriculum Committee to set a minimum standard for genetics education in the context of training in internal medicine. Our objective was to develop a concise outline for a medical genetics curriculum consistent with the RRC-IM guidelines.

Two of the authors (D.L.R.-J. and B.R.K.) identified the organizations that represent medical geneticists, genetic counselors, internists, internal medicine residents, and program direc- 
tors of genetics and internal medicine resident training programs. Representatives from these groups formed the Internal Medicine Residency Training Program Genetics Curriculum Committee (Table 1). Committee members reviewed medical school genetics curricula, genetics curricula from other specialties, curricula from other internal medicine specialties, and other documents. ${ }^{2-5}$

A draft curriculum outline was circulated by D.L.R.-J. and B.R.K., who refereed several rounds of revisions and then edited the draft into the final document. The final document was approved by those organizations with a policy of approving curricula (Table 1). The Association of Program Directors in Internal Medicine and the American Society of Human Genetics contributed representatives but as policy do not approve curricula.

\section{RECOMMENDATIONS FOR A MEDICAL GENETICS CURRICULUM}

\section{Educational purpose}

To provide sufficient training in medical genetics to enable residents in internal medicine to gain an understanding of the following issues:

Implications of the fact that medical genetics is one of the most rapidly changing medical specialties

Fundamental concepts of medical genetics

Genetic counseling as an essential component of genetic care

\section{Teaching methods}

Genetic education should be incorporated longitudinally throughout the 36 months of training. Teaching methods used can include any combination of the following:

Didactic teaching included in the core curriculum, on rounds, and in continuity clinics

Elective clinical experiences in medical genetics
Interactive multimedia CD-ROMs (see Appendix)

Resident attendance at professional meetings with a genetic focus

Resident participation in clinical genetics research

Integration of a medical genetics rotation into the core curriculum of the internal medicine residency training program

Short course in medical genetics

Model patients

Regardless of the type of teaching methods to be used, the committee recommends that teaching be driven by clinical experiences.

\section{Faculty}

The faculty should consist of professionals or physicians with adequate knowledge and experience. Efforts should be made to include interactions with medical geneticists and genetic counselors whenever possible.

\section{Mix of diseases}

It should be emphasized that with the rapid expansion of genetic knowledge, any of hundreds of disorders could be used for study. We recommend that learning be driven by patient interactions.

\section{Patient characteristics}

Patients should include men and women ages 16 and above.

\section{Types of clinical encounters}

Clinical encounters should include both outpatient and inpatient experiences.

\section{Procedures}

Residents should be observed in the construction and interpretation of at least one three-generation pedigree using standardized pedigree nomenclature. Residents should be encour-

Table 1

Groups represented by the Internal Medicine Residency Training Program Genetics Curriculum Committee

\begin{tabular}{|c|c|c|}
\hline Group & Organization representing & Committee member \\
\hline Internal medicine residency training program directors and Internists & $\begin{array}{l}\text { The Association of Program Directors in } \\
\text { Internal Medicine }{ }^{a}\end{array}$ & M.I. Broder \\
\hline Internal medicine residents & $\begin{array}{l}\text { Chief Medical Resident, Mayo Clinic, } \\
\text { 2002-2003 }\end{array}$ & D.L. Riegert-Johnson \\
\hline Internists & $\ldots$ & $\begin{array}{l}\text { M.I. Broder, R.E. Pyeritz, D.L. } \\
\text { Riegert-Johnson }\end{array}$ \\
\hline Genetics residency training program directors & American College of Medical Genetics & B.R. Korf, M. S. Watson, R.L. Alford \\
\hline \multirow[t]{3}{*}{ Medical geneticists } & American College of Medical Genetics & B.R. Korf, M. S. Watson, R.L. Alford \\
\hline & American Society of Human Genetics ${ }^{a}$ & B.J.B. Keats \\
\hline & $\begin{array}{l}\text { Association of Professors of Human and } \\
\text { Medical Genetics }\end{array}$ & R.E. Pyeritz \\
\hline Genetic counselors & National Society of Genetic Counselors & K.E. Ormond \\
\hline
\end{tabular}

${ }^{a}$ The Association of Program Directors in Internal Medicine and the American Society of Human Genetics do not approve curricula as a matter of policy. 
aged to include a pedigree as part of each complete history and physical examination.

\section{Services}

Teaching should occur on both general and specialty medical inpatient services.

\section{Reading lists}

Reading should be directed by clinical experiences. If a reading list is assigned, it should be concise and related to clinical experiences. For selected references, see Appendix.

\section{Pathological material}

No pathological material is required.

\section{Other educational resources to be used}

Table 2 lists useful World Wide Web resources.

\section{Method of evaluation of resident competence}

Currently, resident competence should be assessed by instructors. Unfortunately, standardized objective tools, such as "shelf exams," are not available. Residents should be observed at least once in the construction and interpretation of a three-generation pedigree, and the observer should give feedback to the resident. Residents' genetic counseling skills should be assessed by means of direct observation by a genetic counselor or medical geneticist.

\section{Overcoming barriers to implementation of genetics curriculum}

Several barriers need to be overcome in order to implement a genetics curriculum successfully into internal medicine residency training programs.

One barrier is the perception that medical genetics is limited to the study of young patients with rare disorders. Potential ways of overcoming this perception are to (1) insist on inclusion of "genetic disorders" in differential diagnosis; (2) invite medical geneticists to discuss cases at conferences on mortality and morbidity or clinical pathological correlation; and (3) profile the role of genetics in common adult diseases at medical grand rounds and other conferences.

A second barrier is the lack of faculty with sufficient experience or knowledge. Potential ways to overcome this barrier are to (1) encourage interested faculty to develop knowledge in this area, e.g., with reserved time and sponsorship to meetings; (2) recruit medical geneticists with internal medicine training; (3) use selfdirected educational resources such as CD-ROMs; (4) use genetic counselors and geneticists from other subspecialties, e.g., obstetrics and pediatrics; and (6) use of preprepared teaching materials. Case-based curricular modules designed to integrate genetics into primary care curriculum have been developed by the Society of Teachers of Family Medicine (Table 2). ${ }^{6}$

A third barrier is competition with other required curricular components. Potential solutions for this problem are to (1)

Table 2

Genetic resources on the World Wide Web

\begin{tabular}{lcc}
\hline Resource & World Wide Web address & Description \\
\hline Resources for Health Professionals & & Teaching modules for genetics in primary car \\
Genetics in Primary Care Curriculum & $\begin{array}{c}\text { http://genes-r-us.uthscsa.edu/resources/genetics/ } \\
\text { primary_care.htm } \\
\text { http://www.ncbi.nlm.nih.gov/entrez/ } \\
\text { query.fcgi?db=OMIM } \\
\text { Online Mendelian Inheritance in Man (OMIM) }\end{array}$ & A catalog of human genetic disorders \\
GeneClinics and GeneTests & & $\begin{array}{c}\text { A comprehensive Web site offering current } \\
\text { reviews, directories of laboratories, clinics, } \\
\text { and educational materials }\end{array}$
\end{tabular}

Professional Organizations

American College of Medical Genetics (ACMG)

American Society of Human Genetics (ASHG)

National Society of Genetic Counselors

Association of Professors of Human or Medical Genetics

National Coalition for Health Care Professional Education in Genetics (NCHPEG)

Patient Resources

National Organization of Rare Disorders (NORD)

Genetic Alliance http://www.acmg.net/

http://www.ashg.org/

http://www.nsgc.org/

http://www.faseb.org/genetics/aphmg/aphmg1.htm

http://www.nchpeg.org/

http://www.rarediseases.org/

http://www.geneticalliance.org/
Professional organization of medical geneticists

Professional organization of physicians, scientists, and others involved in the study of human and medical genetics

Professional organization of genetic counselors

Organization for the promotion of human and medical genetics education in North American graduate and medical schools

Organization made up of representatives from a large number of organizations representing health care professionals

Organization devoted to rare disorders, many of which are genetic

Information on support groups for various genetic disorders 
integrate genetic information into preexisting curricula, e.g., integrate discussion of hemochromatosis into material on gastroenterology and (2) develop an elective genetics course focused on the needs of the residents.

\section{Level of resident supervision by faculty members}

Residents should be supervised in ordering all genetic tests and in giving genetic counseling.

\section{Revisions of this proposal}

Revisions should be published biannually, either in print or on the World Wide Web.

\section{LEARNING OBJECTIVES}

The learning objectives have been classified as primary or secondary. Primary objectives are considered important and should be the focus of instruction. Secondary objectives are considered desirable.

\section{Attitudes}

\section{Primary objectives}

Residents must appreciate that the rapid advances being made in medical genetics (as in all areas of medicine) will necessitate lifelong, self-directed learning. In addition, residents should develop attitudes that encompass the following:

Recognition of the responsibility of internists to evaluate and screen for genetic disease

Recognition of the internist's limitations and the importance of referral to genetics specialists

Recognition that patients are best served by a multidisciplinary approach incorporating internists, geneticists, genetic counselors, and subspecialists

Appreciation for the economic, social, psychological, and familial implications of genetic disorders

Recognition of the influence of one's own beliefs and the need to counsel patients in an accurate, nondirective manner with respect for the patients' beliefs and decision-making capacity

\section{Knowledge: foundation}

\section{Primary objectives}

The resident should have a sufficient understanding of the concepts, terminology, and basic techniques to guide self-directed learning, including the following:

Basic principles of human and medical genetics, including genes, chromosomes, and the organization of the human genome

Mendelian inheritance patterns: autosomal dominant, autosomal recessive, $\mathrm{X}$-linked dominant, $\mathrm{X}$-linked recessive

Non-Mendelian inheritance patterns: multifactorial, mitochondrial, trinucleotide repeat expansion (anticipation), imprinting

An understanding of the difference between benign polymorphisms and pathological mutations

An understanding of incomplete penetrance and variable expressivity
Terminology used in medical genetics: allele, incomplete penetrance, genomics, locus heterogeneity, homozygote, hemizygote, heterozygote, compound heterozygote, malformation, mosaicism, nonpaternity, variable expressivity, pleiotropy, polymorphism, pharmacogenetics/genomics, proteomics, single nucleotide polymorphism, trinucleotide repeat expansion, and mutation types, including missense, promoter, nonsense, frameshift, and silent mutations

An appreciation of the complexity of genetic testing, e.g., for cystic fibrosis, in which current commercial tests do not detect $15 \%$ or more of disease-causing mutations

Principles of pharmacogenetics

Implications of the Human Genome Project

Basic understanding of the availability of prenatal diagnostic procedures (e.g., amniocentesis, chorionic villus sampling) and their risks/benefits

\section{Secondary objectives}

Carrier screening: cystic fibrosis, sickle cell disease, thalassemias and other hemoglobinopathies; Tay-Sachs disease, Gaucher disease, and other disorders associated with Jewish ancestry

Therapies for hereditary disorders: gene therapy and product replacement

Laboratory studies and research: karyotype, fluorescent in situ hybridization, polymerase chain reaction, DNA sequencing, mutation analysis, gene mapping and linkage analysis, DNA banking, and DNA microarrays

\section{Knowledge: disease-specific}

\section{Primary objectives}

In reviewing a specific disorder, the primary objectives for the residents are to be able to describe the characteristic phenotype, to have knowledge of the mode of inheritance, and to have knowledge of current options for genetic testing (risk assessment), referral, and treatment.

\section{Secondary objectives}

In reviewing a specific disorder, knowledge of the following is desirable: gene(s) involved, function of involved gene(s), specific mutations and relation to pathogenesis, carrier frequency, penetrance, and appropriate genetic counseling.

\section{Skills}

\section{Primary objectives}

The resident should be trained in the following clinical skills:

Ability to develop an effective self-education program

Documentation of a family history and preparation of a three-generation pedigree (evaluation of ability to construct at least one three-generation pedigree using standard nomenclature)

Use of the medical literature, including: formulation of a clinical question, performance of a literature search, appraisal of an article's validity, evaluation 
of the results, including an understanding of basic probabilities, and application of the results to a clinical situation

Navigation of the World Wide Web to access genetic resources (for example, Online Mendelian Inheritance in Man, GeneTests and GeneClinics, Genetic Alliance)

Basic genetic counseling, including: knowing when to refer at-risk individuals, confidentiality, and informed consent

\section{Secondary objectives}

Recommended additional clinical skills the resident could aquire include:

Risk assessment of patients and families

Duty to inform

Discrimination issues (particular sensitivity to privacy, confidentiality and unfair discrimination in health insurance coverage, and employment)

Providing information to the patient and assessing their subsequent level of understanding

Performance of a focused physical examination for common genetic diseases

Ability to list a "genetic" disease in the differential diagnosis of common medical disorders, e.g., $\alpha 1$-antitypsin deficiency should be included in the differential diagnosis of patients with emphysema.

\section{COMMENT}

Genetics will play an increasing role in the practice of internal medicine. Currently, there is no genetics curriculum available for internal medicine residency training programs. The Internal Medicine Residency Training Program Genetics Curriculum Committee has produced an outline of a curriculum to fill that need. Perhaps the greatest barriers to implementation of this curriculum are the complexity and rapid changes in the field of genetics. Therefore, the curriculum stresses understanding of the vocabulary, concepts, and skills needed to continue self-directed learning. It is our hope that this outline will provide a framework for residency training programs in internal medicine to build their own genetics curriculum.

\section{References}

1. Accreditation Council for Graduate Medical Education. Program requirements for resident education in internal medicine. Available at: http://www.acgme.org/ downloads/RRC_progReq/140pr703.pdf Accessed February 22, 2004.

2. ASHG Report. Report from the ASHG Information and Education Committee: Medical School Core Curriculum in Genetics. ASHG Information and Education Committee. Am J Hum Genet 1995;56:535-537.

3. Curriculum guidelines on the care of the elderly for internal medicine residency training programs. Education Committee of the American Geriatrics Society. Am J Med 1997;103:260-262.

4. Core Competency Working Group of the National Coalition for Health Professional Education in Genetics. Recommendations of core competencies in genetics essential for all health professionals. Genet Med 2001;3:155-159.

5. American Academy of Family Physicians. Recommended Curriculum Guidelines for Family Practice Residents. Available at http://www.aafp.org/x16547.xml. Accessed May 11, 2002
6. Burke W, Acheson L, Botkin J, Bridges K, Davis A, Evans J et al. Genetics in primary care: A USA faculty development initiative. Comm Genet 2002;5:138-146.

\section{APPENDIX}

\section{Selected references}

Electronic CD- ROMs

The New genetics: Courseware for physicians, Twisted Ladder Media, San Francisco, California.

Genetics in clinical practice: A team approach, Interactive Media Laboratory, Dartmouth Medical School, Lebanon, New Hampshire.

Overview of DNA, RNA, transcription, and translation

Tefferi A, Wieben ED, Dewald GW, Whiteman DAH, Bernard ME, Spelsberg, TC. Primer on Medical Genomics. Part II: Background principles and methods in medical genetics. Mayo Clin Proc 2002;77:785-808.

\section{Colon cancer}

Giardiello FM, Brensinger JD, Petersen GM. AGA technical review on hereditary colorectal cancer and genetic testing. Gastroenterology 2001;121:198-213.

Calvert PM, Frucht H. The genetics of colorectal cancer. Ann Intern Med 2002;137:603-612.

\section{Breast cancer}

Rhodes DJ. Identifying and counseling women at increased risk for breast cancer. Mayo Clinic Proc 2002;77:355-360.

\section{Hemochromatosis}

Pietrangelo A. Hereditary Hemochromatosis-A New Look at an Old Disease. N Engl J Med 2004;350:2383-2397.

\section{Thrombosis}

Seligsohn U, Lubetsky A. Medical progress: Genetic susceptibility to venous thrombosis. N Eng J Med 2001;344:1222-1231.

\section{Pedigree construction and analysis}

Bennett $\mathrm{R}$ et al. Recommendations for standardized human pedigree nomenclature. Pedigree Standardization Task Force of the National Society of Genetic Counselors. Am J Hum Genet 1995;56:745-752.

Cook J, Lam W, Mueller RF. Mendelian inheritance. In: Rimoin D, Connor JM, Pyeritz RE, Korf B, editors. Emery and Rimoin's Principles and Practice of Medical Genetics, 4th ed. Churchill Livingston:104-124.

\section{Genetic counseling}

Lloyd FJ, Reyna VF, Whalen P. Accuracy and ambiguity in counseling patients about genetic risk. Arch Intern Med 2001;161:2411-2413.

Evans JP, Skrzynia C, Burke W. The complexities of predictive genetic testing. BMJ 2001;322:1052-1056. 